\title{
Effects of 7 days on an ad libitum low-fat vegan diet: the McDougall Program cohort
}

\author{
John McDougall ${ }^{1 *}$, Laurie E Thomas², Craig McDougall ${ }^{3}$, Gavin Moloney ${ }^{1}$, Bradley Saul ${ }^{4}$, John S Finnell ${ }^{5}$, \\ Kelly Richardson ${ }^{6}$ and Katelin Mae Petersen ${ }^{1}$
}

\begin{abstract}
Background: Epidemiologic evidence, reinforced by clinical and laboratory studies, shows that the rich Western diet is the major underlying cause of death and disability (e.g, from cardiovascular disease and type 2 diabetes) in Western industrialized societies. The objective of this study is to document the effects that eating a low-fat ( $\leq 10 \%$ of calories), high-carbohydrate ( $80 \%$ of calories), moderate-sodium, purely plant-based diet ad libitum for 7 days can have on the biomarkers of cardiovascular disease and type 2 diabetes.
\end{abstract}

Methods: Retrospective analysis of measurements of weight, blood pressure, blood sugar, and blood lipids and estimation of cardiovascular disease risk at baseline and day 7 from 1615 participants in a 10-day residential dietary intervention program from 2002 to 2011. Wilcoxon's signed-rank test was used for testing the significance of changes from baseline.

Results: The median (interquartile range, IQR) weight loss was $1.4(1.8) \mathrm{kg}(\mathrm{p}<.001)$. The median (IQR) decrease in total cholesterol was $22(29) \mathrm{mg} / \mathrm{dL}(\mathrm{p}<.001)$. Even though most antihypertensive and antihyperglycemic medications were reduced or discontinued at baseline, systolic blood pressure decreased by a median (IQR) of 8 (18) $\mathrm{mm} \mathrm{Hg}(\mathrm{p}<.001)$, diastolic blood pressure by a median (IQR) of $4(10) \mathrm{mm} \mathrm{Hg}(\mathrm{p}<.001)$, and blood glucose by a median (IQR) of $3(11) \mathrm{mg} / \mathrm{dL}(\mathrm{p}<.001)$. For patients whose risk of a cardiovascular event within 10 years was $>7.5 \%$ at baseline, the risk dropped to $5.5 \%(>27 \%)$ at day $7(p<.001)$.

Conclusions: A low-fat, starch-based, vegan diet eaten ad libitum for 7 days results in significant favorable changes in commonly tested biomarkers that are used to predict future risks for cardiovascular disease and metabolic diseases.

Keywords: Low-fat diet, Vegan diet, Vegetarian diet, Hypertension, Cholesterol, Hyperlipidemia, Type 2 diabetes, Weight loss, Heart disease

\section{Introduction}

The primary goal of health care should be to decrease all-cause morbidity and mortality. In industrialized societies including those in the United States and Europe, the chief causes of death and disability are noninfectious chronic diseases: atherosclerotic vascular disease, epithelial cell cancers, type 2 diabetes, and autoimmune disorders [1]. The leading underlying cause of these diseases is the rich Western diet, with its emphasis on animalsource foods (i.e., meat, fish, eggs, and dairy foods) and fat-laden and sugary processed foods [2,3]. These diseases

\footnotetext{
* Correspondence: drmcdougall@drmcdougall.com

'Dr. McDougall's Health and Medical Center, PO Box 14039, Santa Rosa, CA 95402, USA

Full list of author information is available at the end of the article
}

are becoming increasingly prevalent in newly industrialized countries in Central America, South America, and Asia as they, too, adopt Western eating styles [4].

The burden of Western disease can be dramatically reduced by eliminating animal-source foods and vegetable fats from the diet and replacing those foods with low-fat, plant-based foods. When a food rationing system during World War I severely restricted the Danish population's intake of meats, dairy products, fats, and alcohol but placed no restrictions on such foods as barley, bread, potatoes, and vegetables, Denmark achieved the lowest mortality rate in its history [5]. Similarly, the mortality due to diabetes in England and Wales decreased sharply while wartime food rationing in both World War I and World War II limited access to animal-source foods and 
fats, only to increase after the those foods became available again in peacetime [6].

A physician can help his or her patients achieve similar benefits by teaching them to eat a low-fat $(\leq 10 \%$ of calories), high-fiber, high-carbohydrate ( $\sim 80 \%$ of calories), purely plant-based (vegan) diet [7-14]. The goal of the present study is to document the improvements in biomarkers of the risk of cardiovascular and metabolic diseases that can be achieved within 7 days when patients are allowed to eat such a diet to satiety under medical supervision in an inpatient setting.

\section{Methods}

This study is a retrospective analysis of the records of patients who attended a physician-supervised 10-day residential program (the McDougall Program) from 2002 to 2011. This ongoing program used Internet marketing to attract patients from a wide geographic area to spend 10 days at a hotel in Santa Rosa, California, where they received dietary counseling and were fed a low-fat ( $\leq 10 \%$ of calories) diet based on minimally refined plant foods ad libitum to satiety. The educational staff included a medical doctor, a registered dietitian, a psychologist, exercise coaches, and cooking instructors. Patients were also given opportunities for light to moderate exercise. No stress reduction techniques or meditations were included in the program.

\section{Medical workup}

Upon admission, a standardized questionnaire was used to ask patients if they had any history of hypertension, coronary artery disease, diabetes, hypothyroidism, multiple sclerosis, hypercholesterolemia, or overweight. The patient's age, sex, and ethnicity were also recorded.

A licensed medical doctor saw all patients on at least 3 occasions during the program, and blood pressure was recorded daily. At baseline, the physician took the patient's history and performed a physical examination. The physician then recommended appropriate changes to each patient's medications. Medications for hypertension and diabetes were reduced or discontinued at baseline in order to lessen the risk of hypotension and hypoglycemia. Cholesterol-lowering medications (statins) were continued throughout the program for those people taking this class of medication upon entering the program.

To facilitate analysis, the following data were recorded according to standardized methods at baseline and on day 7: weight, systolic and diastolic blood pressure, total cholesterol, triglycerides, glucose, blood urea nitrogen, and creatinine. After August 2006, HDL and LDL cholesterol were also measured at baseline and day 7. Body weights were measured with a Detecto ${ }^{\oplus}$ 6800 portable bariatric scale. Blood pressure readings were obtained by a trained operator, manually and/or using an Omron ${ }^{\circledR}$ professional sphygmomanometer. Blood tests were analyzed by using standard medical hospital laboratory procedures.

\section{Menu design}

The hotel's kitchen staff prepared foods according to prescribed guidelines. No animal-derived ingredients (e.g, meat, fish, eggs, or dairy products) and no isolated vegetable oils (e.g, olive, corn, safflower, flaxseed, or rapeseed oil) were used. Meals were based around common starches, including wheat flour products, corn, rice, oats, barley, quinoa, potatoes, sweet potatoes, beans, peas, and lentils, with the addition of fresh fruits and non-starchy green, orange, and yellow vegetables. The macronutrient profile was roughly $7 \%$ fat, $12 \%$ protein, and $81 \%$ carbohydrate by calorie. Meals were served buffet-style, and participants were encouraged to eat to the full satisfaction of their appetite.

To ensure that the foods would be acceptable to palates accustomed to Western diets, small amounts of simple sugars, salt, and various spices were used in meal preparation. Sugar was included in condiment sauces (e.g, ketchup and barbecue sauce) and in the low-fat desserts that were served after evening meals. Patients could also add sugar to their cereal in the morning.

The kitchen staff used minimal salt, mostly in the form of soy sauce, when preparing the meals. The basic meal plan provided roughly $1000 \mathrm{mg}$ of sodium per day. However, saltshakers were provided at meals, and participants were allowed to use regular table salt ad libitum on the surface of their foods for taste. We conclude that even if a patient added a total of a half-teaspoon of salt per day, the diet would still qualify as low-sodium (approximately $2 \mathrm{~g}$ of sodium daily).

\section{Statistical methods}

Data from patients who attended the program from 2002 to 2011 were analyzed in 2014. For patients who attended the program more than once, each visit was regarded as a separate patient record. Records from subjects under the age of 21 were excluded from the analysis. Records with missing data for baseline or day 7 were also excluded.

Before August 2006, tests for HDL and LDL cholesterol were not routinely ordered. Only the records that had baseline and day 7 values were included in the analysis of HDL and LDL. The average total cholesterol values and the change in total cholesterol from day 1 to day 7 for the patients with missing HDL and LDL data were compared to the respective values for the patients with complete data on HDL and LDL.

The change from baseline in biomarkers was analyzed for risk categories based on the patients' baseline variables. The cutoffs for the risk categories were 
arbitrary: total cholesterol <150, 150-179, 180-209, 210 239 , or $\geq 240 \mathrm{mg} / \mathrm{dL}$; triglycerides $<150,150-199,200-499$, or $\geq 500 \mathrm{mg} / \mathrm{dL}$; glucose $<100,100-126$, or $>126 \mathrm{mg} / \mathrm{dL}$; systolic blood pressure $<140$ or $\geq 140 \mathrm{~mm} \mathrm{Hg}$; diastolic blood pressure $<90$ or $\geq 90 \mathrm{~mm} \mathrm{Hg}$; creatinine $<1,1-1.4$, or $>1.4 \mathrm{mg} / \mathrm{dL}$; and blood urea nitrogen $<10,10-20$, or $>20 \mathrm{mg} / \mathrm{dL}$. Because the patients' height was not recorded, the patients could not be stratified according to body mass index. Instead, they were stratified according to their weight, as expressed in standard deviations from the mean for his or her sex.

Because none of the continuous biomarker variables were normally distributed, Wilcoxon's signed-rank tests were used to compare baseline values to day 7 values for all biomarker variables. Each comparison was evaluated for the baseline risk categories, as described above. McNemar's test for paired proportions was conducted to compare the percentage of patients with elevated biomarkers (total cholesterol $\geq 200 \mathrm{mg} / \mathrm{dL}$, SBP $\geq 140 \mathrm{~mm}$ $\mathrm{Hg}$ and DBP $\geq 90 \mathrm{~mm} \mathrm{Hg}$ ) at baseline whose values fell to normal at day 7 to the percentage of patients with normal biomarkers at baseline whose values were considered elevated at day 7 .

In 2013, the American College of Cardiology and American Heart Association published guidelines for estimating a patient's probability of having a cardiac health event (atherosclerotic cardiovascular disease, ASCVD) within 10 years [15]. The guidelines define high ASCVD as a risk $>7.5 \%$. The ASCVD risk can be calculated only for patients whose records include all of the relevant variables: age, total cholesterol, HDL cholesterol, systolic blood pressure, smoking status, diabetes diagnosis, and treatment for high blood pressure. For those patients, the ASCVD risks were calculated twice: once for the baseline values and again for the day 7 values. All of the patients who were on blood pressure medication at baseline were considered to be under treatment for high blood pressure at day 7 as well.

All statistical analyses were conducted by using SAS 9.3 (Cary, NC).

\section{Results}

A total of 1703 patients attended the program from 2002 to 2011. Of these, 46 patients went through the program more than once. The records for the $12 \mathrm{pa}$ tients under the age of 21 were excluded. As a result, a total of 1615 patient-records were included in the analyses. There were 1092 records with baseline and day 7 records for HDL and 1091 with baseline and day 7 records for LDL.

Table 1 shows that the majority of patients were female (65.1\%), white non-Hispanic (92.1\%), and with a median (IQR) age of 58(18) years. Upon admission, $84.3 \%$ of the participants self-reported some history of
Table 1 Demographic variables for full sample $(\mathrm{N}=1615)$

\begin{tabular}{|c|c|}
\hline Variable & Value \\
\hline \multicolumn{2}{|l|}{ Sex, no. (\%) } \\
\hline Male & $563(34.9)$ \\
\hline Female & $1052(65.1)$ \\
\hline \multicolumn{2}{|l|}{ Race/ethnicity, no. (\%) } \\
\hline Asian & $32(2.0)$ \\
\hline Black & $45(2.8)$ \\
\hline Latino & $36(2.2)$ \\
\hline White & $1488(92.1)$ \\
\hline Other & $14(0.9)$ \\
\hline Age, median (IQR) & $58(18)$ \\
\hline$<50$ years, no. $(\%)$ & 459(28.4) \\
\hline 50 to 64 years, no. (\%) & $689(42.7)$ \\
\hline 65 or older years, no. (\%) & $467(28.9)$ \\
\hline \multicolumn{2}{|l|}{ Weight, kg, median (IQR) } \\
\hline Baseline (men) & $93.4(33)$ \\
\hline Baseline (women) & $79.3(29)$ \\
\hline \multicolumn{2}{|l|}{ Disease history } \\
\hline Hypertension & $39.6(640)$ \\
\hline Coronary heart disease & $9.7(157)$ \\
\hline Diabetes & $14.4(232)$ \\
\hline Hypothyroidism & $25.1(405)$ \\
\hline Multiple sclerosis & $3.5(57)$ \\
\hline Overweight & $71.6(1157)$ \\
\hline Hypercholesterolemia & $63.9(1032)$ \\
\hline \multicolumn{2}{|l|}{ Medications at baseline } \\
\hline Blood pressure & $33.6(542)$ \\
\hline Statin & $22.1(357)$ \\
\hline Diabetes & $12.0(194)$ \\
\hline \multicolumn{2}{|l|}{ Medication changes during program } \\
\hline $\begin{array}{l}\text { Reduced or stopped blood pressure medication, } \\
\mathrm{n} / \mathrm{N}(\%)\end{array}$ & $469 / 542(86.5)$ \\
\hline Reduced or stopped diabetes medications, n/N (\%) & 176/194 (90.7) \\
\hline
\end{tabular}

disease. Nearly $64 \%$ reported a history of hypercholesterolemia, and $39.6 \%$ reported a history of hypertension. Most of the patients (79.5\%) reported being on at least 1 medication at baseline for diabetes, hypertension, or elevated cholesterol. Additionally, the majority of the sample self-reported as being overweight (71.6\%).

As shown in Table 2, there were statistically significant decreases in cholesterol (total, HDL, and LDL), weight, systolic and diastolic blood pressure, blood glucose, creatinine, and blood urea nitrogen. The median (IQR) weight loss was $1.4(1.8) \mathrm{kg}$. The median (IQR) decrease in total cholesterol was $22(29) \mathrm{mg} / \mathrm{dL}$. Patients with the highest baseline values for these markers showed the 
Table 2 Comparison of baseline and day 7 biomarker values $(\mathrm{N}=1615)$

\begin{tabular}{|c|c|c|c|c|}
\hline Variable & Baseline, median $\left(\mathrm{IQR}^{a}\right)$ & Day 7, median (IQR) & Change, median $\left(\mathrm{IQR}^{b}\right)$ & $P$-value \\
\hline \multicolumn{5}{|l|}{ Weight, kg } \\
\hline Overall & $84.4(31.4)$ & $82.6(30.4)$ & $-1.4(1.8)$ & $<.001$ \\
\hline Men & $93.2(32.2)$ & $92.5(30.8)$ & $-1.5(2.2)$ & $<.001$ \\
\hline Women & $79.2(29.0)$ & $78.0(28.5)$ & $-1.4(1.6)$ & $<.001$ \\
\hline \multicolumn{5}{|l|}{ Total cholesterol, mg/dL } \\
\hline Overall & $184(56)$ & $162(49)$ & $-22(29)$ & $<.001$ \\
\hline$<150$ at baseline & $133(20)$ & $126(127)$ & $-8(23)$ & $<.001$ \\
\hline 150-179 at baseline & $165(16)$ & $146(25)$ & $-20(24)$ & $<.001$ \\
\hline 180-209 at baseline & $193(14)$ & $169(25)$ & $-25(26)$ & $<.001$ \\
\hline 210-239 at baseline & $221(15)$ & $188(28)$ & $-34(27)$ & $<.001$ \\
\hline$\geq 240$ at baseline & $261(31)$ & $222(43)$ & $-39(29)$ & $<.001$ \\
\hline HDL cholesterol, mg/dL ( $\mathrm{N}=1092)$ & $49(19)$ & $40(16)$ & $-8(8)$ & $<.001$ \\
\hline LDL cholesterol, mg/dL $(\mathrm{N}=1091)$ & $107(49)$ & $92(41)$ & $-16(23)$ & $<.001$ \\
\hline \multicolumn{5}{|l|}{ Systolic blood pressure, $\mathrm{mm} \mathrm{Hg}$} \\
\hline Overall & $128(26)$ & $120(23)$ & $-8(18)$ & $<.001$ \\
\hline Elevated $(\geq 140)$ at baseline & $150(23)$ & $136(18)$ & $-18(18)$ & $<.001$ \\
\hline Normal $(<140)$ at baseline & $120(18.5)$ & $114(20)$ & $-4(16)$ & $<.001$ \\
\hline \multicolumn{5}{|l|}{ Diastolic blood pressure, $\mathrm{mm} \mathrm{Hg}$} \\
\hline Overall & $80(16)$ & $74(12)$ & $-4(10)$ & $<.001$ \\
\hline Elevated $(\geq 90)$ at baseline & $94(10)$ & $83(12)$ & $-11(11)$ & $<.001$ \\
\hline Normal $(<90)$ at baseline & $76(10)$ & $70(13)$ & $-3(10)$ & $<.001$ \\
\hline \multicolumn{5}{|l|}{ Triglycerides, mg/dL } \\
\hline Overall & $118(89)$ & $118(86)$ & $+2(48)$ & .344 \\
\hline Normal $(<150)$ & $92(49)$ & $98(53)$ & $+8(34)$ & $<.001$ \\
\hline Borderline high (150-199) & $169(22)$ & $157.5(73.5)$ & $-11.5(70.5)$ & .004 \\
\hline High (200-499) & $247(81)$ & $216(102)$ & $-46(100)$ & $<.001$ \\
\hline Very high $(\geq 500)$ & $569(109)$ & $360(98)$ & $-294(131)$ & $<.001$ \\
\hline \multicolumn{5}{|l|}{ Glucose, mg/dL } \\
\hline Overall & $92(19)$ & $89(15)$ & $-3(11)$ & $<.001$ \\
\hline$<100$ & $88(9)$ & $86(9)$ & $-1(7)$ & $<.001$ \\
\hline 100 to 126 & $107(10)$ & $99(13)$ & $-8(18)$ & $<.001$ \\
\hline$>126$ & $156(72)$ & $149(84)$ & $-17(45)$ & $<.001$ \\
\hline \multicolumn{5}{|l|}{ Blood urea nitrogen, mg/dL } \\
\hline Overall & $12(5)$ & $9(4)$ & $-3(4)$ & $<.001$ \\
\hline$<10$ & $8(2)$ & $7(3)$ & $-1(2)$ & $<.001$ \\
\hline 10 to 20 & $13(4)$ & $9(3)$ & $-4(3)$ & $<.001$ \\
\hline$>20$ & $23(6)$ & $14(7)$ & $-10(5)$ & $<.001$ \\
\hline \multicolumn{5}{|l|}{ Creatinine, $\mathrm{mg} / \mathrm{dL}$} \\
\hline Overall & $0.8(0.3)$ & $0.8(0.3)$ & $0(0.1)$ & $<.001$ \\
\hline$<1$ & $0.8(0.2)$ & $0.8(0.2)$ & $0(0.1)$ & .100 \\
\hline 1 to 1.4 & $1.0(0.2)$ & $1.0(0.1)$ & $0(0.1)$ & $<.001$ \\
\hline$>1.4$ & $1.6(0.3)$ & $1.5(0.3)$ & $0.1(0.2)$ & .002 \\
\hline 10-year risk for hard ASCVD,\% $(\mathrm{N}=1092)$ & $4.0(9.0)$ & $3.9(9.0)$ & $-1.0(1.0)$ & $<.001$ \\
\hline Patients with elevated risk at baseline, percentage points $(N=403)$ & $18.0(17.5)$ & $16.2(16)$ & $-2.0(4.1)$ & $<.001$ \\
\hline
\end{tabular}

$a_{\mathrm{IQR}}=$ interquartile range.

${ }^{b}$ Notice that the change column is not the difference between the baseline and day 7 medians. The change score provided by the Wilcoxon signed rank test reflects the paired difference in the 2 scores. 
greatest improvements at day 7 . For example, the median change in total cholesterol was $-39 \mathrm{mg} / \mathrm{dL}$ for patients with a baseline value of $\geq 240 \mathrm{mg} / \mathrm{dL}$ but only $-8 \mathrm{mg} / \mathrm{dL}$ for patients with a baseline value of $<150 \mathrm{mg} / \mathrm{dL}$. Systolic blood pressure dropped by $18 \mathrm{~mm} \mathrm{Hg}$ in patients who had elevated systolic pressure at baseline but by only $4 \mathrm{~mm} \mathrm{Hg}$ in patients whose systolic pressure was normal at baseline. The same was true for diastolic blood pressure (11 mm Hg drop compared to a $3 \mathrm{~mm} \mathrm{Hg}$ drop). Even patients whose biomarkers were normal at baseline showed significant improvements at the end of the 7-day period on nearly every measure (except for patients with creatinine levels less than $1 \mathrm{mg} / \mathrm{dL}$ at baseline), although the greatest improvements were in the patients whose biomarkers were most abnormal at baseline.

Table 1 shows the number of patients taking medication at baseline and the number who reduced or discontinued medications during the program. Of those on medication upon entering the program, $86.5 \%$ of patients on blood pressure medications and $90.7 \%$ of patients on diabetes medications reduced their dosage or discontinued the medication entirely.

The 10-year risk of ASCVD for the full sample (where HDL cholesterol data were available for both baseline and day $7, \mathrm{~N}=1092$ ) experienced a median decrease of 1 percentage point $(\mathrm{IQR}=1.0 ; \mathrm{p}<.001)$. However, among patients whose risk was elevated (i.e., $>7.5 \%$ ) at baseline, the median decrease in 10-year risk at day 7 was 2.00 percentage points (IQR, 4.1; $\mathrm{p}<.001$ ).

Table 3 shows that the percentage of patients whose blood pressure and total cholesterol went from elevated at baseline to normal at day 7 was much higher than the percentage of patients whose values went from normal to elevated in the same timeframe $(\mathrm{p}<.001$, McNemar's test).

\section{Discussion}

This study documents that a low-fat ( $\leq 10 \%$ of calories), high-fiber, high-carbohydrate ( $\sim 80 \%$ of calories), vegan diet allows overweight patients to lose weight even if they eat enough food to feel completely satisfied, ad libitum. From eating such a diet for 7 days, the participants

Table 3 Biomarker shifts from elevated to normal and vice versa from baseline to day 7

\begin{tabular}{llll}
\hline Biomarker & $\begin{array}{l}\text { Elevated at baseline } \\
\text { and normal on } \\
\text { day 7, no. (\%) }\end{array}$ & $\begin{array}{l}\text { Normal at baseline } \\
\text { and elevated at } \\
\text { day 7, no. (\%) }\end{array}$ & P-value $^{\boldsymbol{a}}$ \\
\hline $\begin{array}{l}\text { Diastolic blood } \\
\text { pressure }\end{array}$ & $223(13.8)$ & $36(2.2)$ & $<.001$ \\
$\begin{array}{l}\text { Systolic blood } \\
\text { pressure }\end{array}$ & $312(19.3)$ & $58(3.6)$ & $<.001$ \\
Total cholesterol & $323(20.0)$ & $24(1.5)$ & $<.001$ \\
\hline
\end{tabular}

${ }^{a}$ McNemar's test. lost a median of $1.4 \mathrm{~kg}$ (3 pounds) and had significant improvements in blood pressure, blood lipids, and blood sugar. The patients who were the most overweight and had the most unfavorable biomarkers at baseline had the largest favorable responses. The improvements in blood pressure and blood sugar are even more remarkable when one considers that most of the patients discontinued their antihypertensive and antihyperglycemic medication at baseline.

This kind of dramatic, early success can be important for maintaining patients' motivation to adhere to the diet. These rapid results could also motivate physicians to prescribe diet therapy before resorting to the pharmacy for helping their patients. The present study also provides a practical model for health promotion within the healthcare system: an intensive week-long residential educational program. The long-term effectiveness and cost-effectiveness of this approach for managing Western diseases, in comparison with the current approaches that focus on prescription medication and major surgery, deserve further study. We believe that this simple dietary approach can improve patients' health and ultimately reduce healthcare costs.

The diet used in this study differs significantly from some conventional approaches to weight loss. Note, however, that the potential therapeutic value of plant-based diets has been mentioned in the American Diabetes Association's clinical practice recommendations [16] as well as in a position paper issued by the American Dietetic Association [17]. The diet in this study was $<10 \%$ fat by calorie, whereas the American Heart Association recommends that fat should account for $25 \%$ to $35 \%$ of calories [18]. Unlike many popular weight loss regimens, the diet used in this study does not use calorie counting or other portion control strategies for weight loss.

When conventional dietary approaches fail to reverse type 2 diabetes and cardiovascular disease, prescription medications are used to control the biomarkers of chronic disease. Unfortunately, the drug-induced improvements in biomarkers do not always translate into reduced mortality [19]. Paradoxically, the attempts to use prescription medications intensively to help people with type 2 diabetes achieve glycosylated hemoglobin levels similar to those found in healthy people have led to an increase in mortality as well as to weight gain and increases in episodes of hypoglycemia [20]. In contrast, a low-fat vegan diet improves biomarkers by removing the cause of Western diseases: the rich Western diet.

Uncontrolled studies like this one can provide valuable evidence in situations where randomized, blinded clinical trials have not been or cannot be performed [21]. This study provides valuable evidence of the efficacy of a lifestyle intervention: the maximum results that patients can achieve under ideal circumstances (i.e, restricted 
food choices). Nevertheless, this study has some significant limitations. One concern is that the moderate exercise allowed during the program could have contributed to the observed weight loss. Another concern is the timeframe, which was too short to show whether the improvements in biomarkers would be sustained or would ultimately translate into decreases in morbidity and mortality. However, longer studies of high-carbohydrate, plant-based diets in an outpatient setting have also shown promising results [7-14]. In contrast, prospective cohort studies have shown that low-carbohydrate diets increase all-cause mortality and the risk of cardiovascular events [22-24].

Perhaps the biggest limitation of the vegan diet studies comes from the selection of the participants. Subjects who choose to participate in these studies are willing to try a low-fat vegan diet to improve their health and/or appearance. Thus, they may be more likely than the general population to adhere to the diet.

In conclusion, in this retrospective study, we observed that an energy-unrestricted low-fat, starch-based, vegan diet consumed in a controlled environment for 7 days resulted in substantial favorable changes in commonly tested biomarkers that are used to predict future risks for cardiovascular disease and metabolic diseases. The results also suggest a model for a cost-effective therapy to offer patients commonly seen in medical practices today.

\section{Supporting data}

The supporting data from this study will be available in a separate file for publication.

\section{Abbreviations}

ASCVD: Atherosclerotic cardiovascular disease; HDL: High-density lipoprotein; IQR: Interquartile range; LDL: Low-density lipoprotein.

\section{Competing interests}

John McDougall is the author of several books on the role of diet for the prevention and management of chronic disease. None of the other authors have any competing interests, financial or otherwise, to report.

\section{Authors' contributions}

JM is the founder of the McDougall Program and the investigator of the study. He had full access to all of the data in the study and takes responsibility for the integrity of the data and the accuracy of the data analysis. GM and KMP compiled the data from patient records. KR and JSF performed the statistical analysis. LT wrote the manuscript. CM, BS, and KMP revised the manuscript. All authors read and approved the final manuscript.

\section{Acknowledgement}

Research support: The McDougall Research and Education Foundation.

\section{Author details}

'Dr. McDougall's Health and Medical Center, PO Box 14039, Santa Rosa, CA 95402, USA. ${ }^{2}$ Madison, NJ, USA. ${ }^{3}$ Healthy Living Program, Northwest Permanente, Beaverton, OR, USA. ${ }^{4}$ Department of Biostatistics, University of North Carolina, Chapel Hill, NC, USA. ${ }^{5}$ AOMA Graduate School of Integrative Medicine, Austin, TX, USA. ${ }^{6}$ Richardson Statistical Consulting, lowa City, IA, USA
Received: 7 July 2014 Accepted: 24 September 2014

Published: 14 October 2014

\section{References}

1. The Top 10 Causes of Death. Geneva, Switzerland: World Health Organization; 2014

2. Chen J, Campbell TC, Li J, Peto R: Diet, Life-Style and Mortality in China: A Study of the Characteristics of 65 Chinese Counties. Ithaca, NY: Cornell University Press; 1990.

3. Menotti A, Kromhout D, Blackburn H, Fidanza F, Buzina R, Nissinen A: Food intake patterns and 25-year mortality from coronary heart disease: crosscultural correlations in the Seven Countries Study. The Seven Countries Study Research Group. Eur J Epidemiol 1999, 15:507-515.

4. Kida K, Takemoto K, Yang SW, Likitmaskul S: Effects of Western diet on risk factors of chronic diseases in Asia. In Preventive Nutrition: The Comprehensive Guide for Health Professionals. Edited by Bendich A, Deckelbaum RJ. New York, NY: Humana Press; 2005.

5. Hindhede M: Vegetarian experiment with a population of 3 million: the effect of food restriction on mortality in Copenhagen during war. JAMA 1920, 74

6. Young FG, Richardson KC, Lawrence RD, Himsworth HP, Harris H, Crofton WM, Walker M, Hilton SM: Discussion on the cause of diabetes. Proc $R$ Soc Med $1949,42 \cdot 321-330$

7. Englert HS, Diehl HA, Greenlaw RL, Willich SN, Aldana S: The effect of a community-based coronary risk reduction: the Rockford CHIP. Prev Med 2007, 44:513-519.

8. Hays NP, Starling RD, Liu X, Sullivan DH, Trappe TA, Fluckey JD, Evans WJ: Effects of an ad libitum low-fat, high-carbohydrate diet on body weight, body composition, and fat distribution in older men and women: a randomized controlled trial. Arch Intern Med 2004, 164:210-217.

9. Roberts CK, Barnard RJ: Effects of exercise and diet on chronic disease. J Appl Physiol 2005, 98:3-30.

10. Beard CM, Barnard RJ, Robbins DC, Ordovas JM, Schaefer EJ: Effects of diet and exercise on qualitative and quantitative measures of LDL and its susceptibility to oxidation. Arterioscler Thromb Vasc Biol 1996, 16:201-207.

11. Ferdowsian HR, Barnard ND: Effects of plant-based diets on plasma lipids. Am J Cardiol 2009, 104:947-956.

12. Kempner W: Treatment of hypertensive vascular disease with rice diet. Arch Intern Med 1974, 133:758-790.

13. Ornish D, Weidner G, Fair WR, Marlin R, Pettengill EB, Raisin CJ, Dunn-Emke S, Crutchfield L, Jacobs FN, Barnard RJ, Aronson WJ, McCormac P, McKnight DJ, Fein JD, Dnistrian AM, Weinstein J, Ngo TH, Mendell NR, Carroll PR: Intensive lifestyle changes may affect the progression of prostate cancer. J Urol 2005, 174:1065-1069.

14. Barnard RJ, Massey MR, Cherny S, O'Brien LT, Pritikin N: Long-term use of a high-complex-carbohydrate, high-fiber, low-fat diet and exercise in the treatment of NIDDM patients. Diabetes Care 1983, 6:268-273.

15. Goff DC Jr, Lloyd-Jones DM, Bennett G, Coady S, D'Agostino RB Sr, Gibbons R, Greenland P, Lackland DT, Levy D, O'Donnell CJ, Robinson J, Schwartz JS, Shero ST, Smith SC Jr, Sorlie P, Stone NJ, Wilson PW: ACC/AHA guideline on the assessment of cardiovascular risk: a report of the American College of Cardiology/American Heart Association Task Force on Practice Guidelines. Circulation 2013, 2013:

16. Evert AB, Boucher JL, Cypress M, Dunbar SA, Franz MJ, Mayer-Davis EJ, Neumiller JJ, Nwankwo R, Verdi CL, Urbanski P, Yancy WS Jr: Nutrition therapy recommendations for the management of adults with diabetes. Diabetes Care 2014, 37(Suppl 1):S120-S143.

17. Craig WJ, Mangels AR, American Dietetic Association: Position of the American Dietetic Association: vegetarian diets. J Am Diet Assoc 2009, 109:1266-1282.

18. Know your fats. [https://www.heart.org/HEARTORG/Conditions/Cholesterol/ PreventionTreatmentofHighCholesterol/Know-Your-Fats_UCM_305628_ Article.jsp]

19. Abramson JD, Rosenberg HG, Jewell N, Wright JM: Should people at low risk of cardiovascular disease take a statin? BMJ 2013, 347:f6123.

20. Boussageon R, Bejan-Angoulvant T, Saadatian-Elahi M, Lafont S, Bergeonneau C, Kassai B, Erpeldinger S, Wright JM, Gueyffier F, Cornu C: Effect of intensive glucose lowering treatment on all cause mortality, cardiovascular death, and microvascular events in type 2 diabetes: meta-analysis of randomised controlled trials. BMJ 2011, 343:d4169.

21. Dreyer NA, Tunis SR, Berger M, Ollendorf D, Mattox P, Gliklich R: Why observational studies should be among the tools used in comparative effectiveness research. Health Aff (Millwood) 2010, 29:1818-1825. 
22. Fung $T$, van Dam RM, Hankinson SE, Stampfer M, Willett WC, Hu FB: Low-carbohydrate diets and all-cause and cause-specific mortality: two cohort studies. Ann Intern Med 2010, 153:289-298.

23. Lagiou P, Sandin S, Lof M, Trichopoulos D, Adami HO, Weiderpass E: Low carbohydrate-high protein diet and incidence of cardiovascular diseases in Swedish women: prospective cohort study. BMJ 2012, 344:e4026.

24. Noto H, Goto A, Tsujimoto T, Noda M: Low-carbohydrate diets and all-cause mortality: a systematic review and meta-analysis of observational studies. PLoS One 2013, 8:e55030.

doi:10.1186/1475-2891-13-99

Cite this article as: McDougall et al:: Effects of 7 days on an ad libitum low-fat vegan diet: the McDougall Program cohort. Nutrition Journal 2014 13:99

\section{Submit your next manuscript to BioMed Central and take full advantage of:}

- Convenient online submission

- Thorough peer review

- No space constraints or color figure charges

- Immediate publication on acceptance

- Inclusion in PubMed, CAS, Scopus and Google Scholar

- Research which is freely available for redistribution 